for controlling various metallurgical operations and products, as a necessary aid in the construction of constitutional diagrams of alloys systems, as a means for supplying important evidence bearing on the failure of metallic materials in use and on the service deterioration of certain types of alloys.

The nature of the metallurgical tests and investigations for which the Bureau of Standards is equipped is also briefly discussed.

\title{
PREPARATION OF GALACTOSE.
}

\author{
By E. P. Clark.
}

[ABSTRACT.]

IN preparing galactose $1500 \mathrm{~g}$. of lactose are dissolved in $375^{\circ}$ c.c. of hot water containing $75 \mathrm{~g}$. of concentrated sulfuric acid. The solution is brought to a boil and then simmered for two hours. A thin paste of barium carbonate is then added to the hot solution until it reacts neutral to Congo paper. The precipitate of barium sulfate is allowed to settle over night, after which as much as possible of the supernatant liquid is drawn off: This liquid is filtered through a thin layer of active carbon placed on moistened filter paper in a Buchner funnel. When all has passed through, the precipitate is placed on the filter, drained as dry as possible, and finally washed by drawing a little water through it. The filter, prepared with a small amount of carbon, as outlined, clarifies the solution and at the same time prevents the sulfate from passing through and gives a relatively rapid filtration.

The filtrate is concentrated under diminished pressure until it has a weight of $1650 \mathrm{~g}$. If a refractometer is available the concentrated syrup should have a refractive index between $1.5 \mathrm{I} 2 \mathrm{O}$ and I 5 I 25 . The very thick syrup is warmed to between 60 and $70^{\circ}$. C. and 250 c.c. of ethyl alcohol are dissolved in it by vigorous shaking. The solution is then poured into a beaker or jar and the remaining syrup is washed from the flask with 500 c.c. of methyl alcohol this is done best by adding the methyl alcohol to the flask portionwise, warming and shaking in a water bath. The whole solution is thoroughly mixed, seeded with some pure galactose crystals, and allowed to crystallize.

\footnotetext{
${ }^{8}$ Sciertific Paper No. 416.
} 
The crystallization is generally complete in about four days, after which the galactose is filtered off, washed with a little methyl alcohol, then with 85 per cent. ethyl alcohol, and finaily with 95 per cent. alcohol. It is then dried. The yield of this crude sugar is about 27 per cent. of the lactose taken.

In order to purify the crude galactose, it is dissolved in water, making about a 25 per cent. solution. To this is added a few c.c. of glacial acetic acid. It is then concentrated under diminished pressure to about 75 per cent. total solids, warmed to 60 or $70^{\circ} \mathrm{C}$., transferred to a beaker and 95 per cent. alcohol added to saturation. Almost immediately the contents of the flask become solid. After allowing to stand over night, it is filtered from the mother liquor, washed and dried. The yield is generally 82 to 83 per cent. of the crude sugar taken.

\title{
THE SPECTRAL DISTRIBUTION OF ENERGY REQUIRED TO EVOKE THE GRAY SENSATION.
}

\author{
By Irwin G. Priest.
}

[ABSTRACT.]

THE need of a rigidly defined standard of "white light" has long been felt, the only such "standards" in use being more or less arbitrary and without agreement among themselves. In order to be accepted as such, a standard of white light should be described in terms of the Planckian distribution of energy required to evoke the hueless sensation of brilliance commonly called " white" or "gray." Although a number of incandescent solid sources approximate in their spectral distribution of energy to the condition imposed by this formula, no source can be raised to a sufficiently high temperature to produce the sensation of white. The problem is not impossible of solution, however, for means have been found by which the spectral distribution of a source can be modified so that the distribution among the wave-lengths in the visible spectrum can be made to assume the form required by Planck's formula, for any temperature from 4000 to $7000^{\circ} \mathrm{K}$, inclusive. This is accomplished by means of rotatory dispersion, produced by a system of nicols and quartz plates.

\footnotetext{
- Scientific Paper No. 4I\%.
} 